\title{
Políticas públicas puestas en ejecución por el estado Colombiano para la integración de los migrantes Venezolanos
}

\section{Public policies implemented by the Colombian state for the integration of Venezuelan migrants}

\author{
(iD) \\ Paola Margarita Carvajal Muñoz \\ Universidad De La Costa, Colombia \\ paolacarvajal83@hotmail.com \\ (iD) \\ Eduardo Antonio Palencia Ramos \\ Universidad Simón Bolívar, Colombia \\ epalencia@unisimonbolivar.edu.co
}

\author{
(iD \\ Beliña Herrera Tapias \\ Universidad De La Costa, Colombia \\ bherrera3@cuc.edu.co \\ Mireya Peréz Núñez \\ Universidad De La Costa, Colombia \\ mireiopuntacardon@gmail.com
}

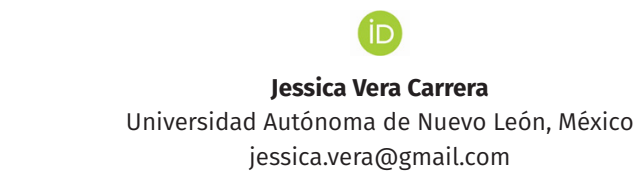

Recibido: 02 de agosto de 2021 / Aceptado: 07 de diciembre de 2021 https://doi.org/10.17081/just.26.40.5306

La migración es un fenómeno que ha sido estudiado de forma constante en la actualidad, su interés estriba fundamentalmente en que es sufrido por millares de personas que buscando satisfacer sus necesidades básicas deciden partir a otras latitudes. La causa principal del éxodo son las crisis institucionales derivadas de políticas de gobierno y medidas económicas que generan un detrimento en la sociedad. Venezuela se ha convertido en este último tiempo en el referente de una migración masiva. Por consiguiente, países como Colombia han diseñado políticas públicas encaminadas a regularizar la migración a través de la expedición de decretos nacionales y locales, además de sentencias de la corte constitucional, para garantizar su permanencia, acceso a la salud, educación y nacionalidad. En este sentido el presente artículo aborda este panorama desde la óptica jurídica, social y política. La metodología es histórica retrospectiva, el enfoque es cualitativo, de tipo documental de campo; en consecuencia se delimita su estudio al municipio de Sabanalarga-Atlántico, por ser receptor de migrantes con y sin arraigo.

KEY WORDS: migración, políticas públicas, migrantes venezolanos, nacionalidad.

\begin{abstract}
Migration is a phenomenon that has been studied constantly today, its interest is fundamentally that it is suffered by thousands of people who, seeking to satisfy their basic needs, decide to go to other latitudes. The main cause of the exodus are the institutional crises derived from government policies and economic measures that generate a detriment to society. Venezuela has recently become the benchmark for mass migration. Consequently, countries like Colombia have designed public policies aimed at regularizing migration through the issuance of national and local decrees, in addition to constitutional court rulings, to guarantee their permanence, access to health, education and nationality. In this sense, this article addresses this panorama from a legal, social and political perspective. The methodology is historical retrospective, the approach is qualitative, of the field documentary type; Consequently, its study is limited to the municipality of Sabanalarga-Atlántico, as it is a recipient of migrants with and without roots.
\end{abstract}

PALABRAS CLAVE: migration, public policies, Venezuelan migrants, nationality.

Como Citar: Carvajal Muñoz, P. M., Herrera Tapias, B. A., Palencia Ramos, E. A., Peréz Núñez, M. J., \& Vera Carrera, J. (2021) Políticas públicas puestas en ejecución por el estado Colombiano para la integración de los migrantes Venezolanos. Justicia, 26(40), 206-221. https://doi.org/10.17081/just.26.40.5306 


\section{Introducción}

Los países que componen a la región latinoamericana, secularmente, han experimentado diversos cambios de índole política, social y económica, producto, a grandes rasgos del autoritarismo con el que se ha ejercido el poder gubernamental. Lo anterior se coadyuva, entre otros factores, por dos consideraciones que a continuación se exponen: 1) el mesianismo endilgado a ciertas personas, partir de las cuales se construye un liderazgo casi cerril y obcecado. Esta visión gregaria de la política conlleva a que no se sigan planes o programas sino visiones o formulaciones personalistas. Por consiguiente se considera, a ciertos dirigentes como los únicos capaces de resolver irregularidades dejadas por otros gobiernos. En ese orden de ideas, periódicamente se está en la búsqueda de "salvadores". 2) la cosmovisión ciudadana respecto a la actividad política, sustancialmente se hace referencia a la división ideológica, para algunos polarizada, presente en estos países. Las luchas intestinas son frecuentes y perecieren irreconciliables, esto forma parte de un escenario que en veces destruye cualquier intento de disenso u oposición sobre los gobiernos de turno.

Las consideraciones antes reseñadas, como se mencionó, no son elemento privativo de ciertas naciones en la región, tampoco obedecen exclusivamente a una vertiente ideológica, son aspectos comunes y generales, arrostradas endémicamente. Ante los eventos suscitados, aunado a otros tipos de problemas como la pobreza, desigualdad e inequidad, resultan casi que imposible, gestiones basadas en la sensatez y racionalidad, que se aparten de los intereses del mandatario de turno y sus copartidarios, por ende, proponer y mucho menos, otorgar soluciones loables puede ser causa de amenazas y hasta exilios.

Las deficiencias o éxitos de un estado dirigente se ven reflejadas en la situación de bienestar que poseen sus integrantes, y en connivencia a ello, puede entenderse como un perogrullo, que la pauperización social se erige como la muestra prístina de malas gestiones endógenas y exógenas. Es simple entender que si un ser humano no encuentra la solución de sus necesidades básicas en su lugar de origen, se ve ante la triste e imperiosa necesidad de emigrar, dejando atrás un cúmulo de aspectos que pasan desde lo sentimental hasta lo económico. En Latinoamérica son muchos los países que han experimentado estas situaciones, puede mencionarse a Colombia como el ejemplo más resaltante, principalmente por la violencia que ha arrostrado este país durante décadas. Esta nación, históricamente fue foco de emigrantes, siendo los países fronterizos los de mayor recepción, particularmente Venezuela. Lo anterior acarreaba un coste social y económico ingente por el país que los acogiese, específicamente porque en su mayoría las personas desplazadas eran de recursos económicos escasos. En un principio, este fenómeno parecía ser unigénito de Colombia, sin embargo, lamentablemente se ha extendido a otras naciones de la región como Venezuela. En esta etapa de la historia resulta paradójico porque este país fue receptor de migrantes, colombianos en gran parte como se mencionó, y también porque es precisamente Colombia quien se transforma en el país donde la mayoría de ciudadanos venezolanos han optado como destino.

El éxodo de ciudadanos venezolanos hacia Colombia durante el segundo mandato del presidente Nicolás Maduro, fue masivo de acuerdo a los datos de Migración Colombia-El Departamento Administrativo Nacional de Estadísticas (DANE, 2005-2016, p. 30) la cifra de emigrantes venezolanos para 2016 fue de 15.544, los cuales han venido migrando al país, en gran parte, por la difícil coyuntura económica, política y social de Venezuela. Según el documento (CONPES-3950, 2018) La Migración venezolana ha aumentado de manera significativa, registrada en 171.783 migrantes en mayo del 2017 y para el 30 de septiembre de 2018 la cifra de migrantes establecidos en Colombia incrementó a 1.032.016,

Por otra parte, estas estadísticas muestran como el flujo migratorio de venezolanos llegó a superar el medio millón de ciudadanos en el año de 2018, cifras que muestran la amplitud de la emigración en cuanto 
al número exacto de la totalidad de emigrados en esa década. Igualmente, hasta septiembre de 2019 el DANE evaluó que 1.641 .000 venezolanos vivían en Colombia., (Migración Colombia, 2019).

Este movimiento de nacionales venezolanos personifica algo que era, tal vez, la primera crisis migratoria de venezolanos para el mundo que emergía durante el mandato del socialismo del siglo XXI. Igualmente, "la migración venezolana" como se conoce en el mundo sirve como un precedente histórico para los estudios actuales sobre migraciones del siglo XXI en Latinoamérica.

La crisis política, económica y social en Venezuela dio comienzo a la migración de cientos de miles de personas. La intensa llegada de venezolanos representó un gran desafío para el gobierno colombiano y para los migrantes que deben adaptarse a una nueva sociedad.

Esta investigación busca contribuir en un campo de estudios donde se está construyendo la información sobre la diáspora del pueblo venezolano por causa de la crisis político, social y económico del país petrolero considerado como uno de los más ricos de Sur América.

La importancia del presente artículo estriba en que son pocos los estudios que se han dedicado al análisis de la situación migrante en territorio colombiano, específicamente en lo que atañe al municipio de Sabanalarga departamento del Atlántico, ya que es un contexto poblacional históricamente arraigado a Venezuela.

En atención a los planteamientos señalados, esta producción científica tiene como propósito general analizar las políticas públicas puestas en ejecución por el Estado colombiano para la integración de los migrantes venezolanos. En este estudio en primer lugar se presenta la metodología, posteriormente se caracteriza la colonia de exiliados venezolanos en Colombia y en el Municipio de Sabanalarga, seguidamente, se refiere a las políticas públicas de inclusión de los venezolanos en el territorio colombiano a la luz de las decisiones de la corte constitucional y las resoluciones del ministerio de relaciones exteriores en materia de legalización, salud y el otorgamiento de la ciudadanía colombiana a los venezolanos recién nacidos en Colombia, (El riesgo de apatridia de los hijos de migrantes venezolanos) seguidas de las conclusiones.

\section{Metodología}

Para realizar esta investigación se diseñará una estrategia metodológica con un predominio del método cualitativo. La metodología cualitativa se propone entender los fenómenos sociales incorporando distintas herramientas como: la inducción analítica, el análisis del discurso, la observación directa, entre otros, así como la propia perspectiva de los actores a partir de examinar el modo en que experimentan el mundo en un contexto histórico definido. Quienes deciden desarrollar la investigación cualitativa asumen un compromiso ingente ya que en este campo se abarca, para la obtención de resultados holísticos, aspectos empíricos y documentales tal como lo plantea (Hernández, 2015):

El proceso de investigación refleja la complejidad de lo social, abarcando una gran diversidad de datos e informaciones que el investigador debe manejar y analizar y que no se limitan a los relatos de los informantes, sino que también incluyen (o deberían incluir) como mínimo, las vivencias del investigador, la información de contexto, la naturaleza de la organización social en que se producen o la estructura relacional que la caracteriza. (Hernández, 2015, p.454) 
Desde la postura epistemológica que orienta este trabajo con una visión cualitativa se encuentra en sintonía con el construccionismo social (Basilio, 2009), que permite desde sus premisas realizar un abordaje de ese grupo de migrantes que se construye a través de realidades relativas, individuales y comunes.

Las fuentes que recopila esta investigación son: entrevistas orales realizadas por los investigadores bajo un guion específico referido al problema de investigación; reportajes y entrevistas realizados por otros autores y publicados en distintos momentos; documentos de organizaciones de exiliados, de derechos humanos; revistas y prensa periódica colombiana desde 2016; documentos diplomáticos, sentencias judiciales, comunicados de organismos internacionales; bibliografía de época e histórica.

Para reconstruir e interpretar la mayoría de las interrogantes que guían la investigación, el cúmulo de material informativo se someterá a un análisis documental, un análisis de contenido, así como, de contraste de fuentes. Para ello, será necesario organizar el corpus de acuerdo con parámetros y técnicas de recolección de información cualitativa, surgidas del análisis de bibliografía, de documentación y de entrevistas a informantes clave.

\section{Antecedentes}

En este acápite se enunciaran una serie de investigaciones respecto a la migración venezolana interna en el continente americano y en las Islas del Caribe, con el fin de hacer un estudio sustancial sobre el tema. Habida cuenta de lo anterior, se toman las siguientes:

En cuanto a las migraciones del siglo XX. (Gutiérrez Guerra, 2011) realizó el artículo intitulado: El debate científico sobre Migración Internacional y Desarrollo. Arguye que un elemento principal de los últimos lustros del siglo XX fue sin dudas la eclosión de la crisis migratoria como núcleo de debates internacionales. Los éxodos humanos, que actualmente se trataron someramente, según necesidades específicas, se plantean ahora como un fenómeno que es atendido por todos los países.

Conviene también señalar que se presenta un desacierto en los productos científicos sobre el tema migratorio, ya que prevalece un análisis reducido y superficial del fenómeno, igualmente, las soluciones de los organismos internacionales, como la Organización Mundial para las Migraciones (OIM), "responden a las posiciones de las naciones más ricas y las soluciones que brindan aumentan los niveles de dependencia de los países en vías de desarrollo y minimizan sus posibilidades de desarrollo autónomo".

Un artículo muy significativo es el de (Durand, 2009), referente a los Processes of Migration in Latin America and the Caribbean (1950-2008), ya que otorga una concepción holística de los fenómenos migratorios suscitados en América Latina y la situación en algunos países de la región que han pasado a ser generadores de migrantes.

Seguidamente, se trae a colación el trabajo de (Álvarez de Flores, 2007), en él se elabora una disquisición sobre la Evolución histórica de las migraciones en Venezuela. En un breve recuento, la autora explica que la crisis experimentada durante la década de los 80' en Venezuela hizo que muchos extranjeros retornaran a su país de origen, salvo a aquellos cuyas naciones pasaban por situaciones políticas y sociales turbulentas, como es el caso de los chilenos.

En referencia a la discusión sobre paradigmas teóricos y conceptuales, (Ortín, 2019), presenta el artículo denominado; Migraciones, desarrollos teóricos, evidencias empíricas y consistencias conceptuales, en esta investigación se trata de elucidar por qué hablar de paradigmas teóricos y conceptuales en vez de 
Paola Margarita Carvajal Muñoz, Beliña Anner Herrera Tapias, Eduardo Antonio Palencia Ramos, Mireya Peréz Núñez, Jessica Vera Carrera

teorías. El autor establece dos razones e indica que las migraciones son fenómenos sociales que abarcan la esfera económica, social, política y cultural. En este sentido, las teorías no logran abarca la complejidad del fenómeno.

Las investigaciones citadas permiten obtener una visión general del proceso migratorio venezolano en diversos países, no obstante, la presente disquisición es de gran significancia ya que aporta insumos históricos para la recomposición y trayectoria del éxodo venezolano en los pocos años de exilio que llevan en países donde tendrán que establecerse y pasar a formar parte igualitaria en la sociedad de acogida.

Por otro lado, se hace necesario resaltar que este conocimiento es inevitable registrarlo y guardarlo en la memoria colectiva de los ciudadanos de Venezuela, ya que actualmente se trata de sistematizar la acentuada migración de venezolanos hacia diferentes países del mundo, anteriormente era lo contrario, migrantes de todas partes del mundo se instalaban en la rica Venezuela petrolera, de allí, la importancia histórica de este estudio.

\section{Factores determinantes de la emigración venezolana a Colombia}

Con respecto a la migración desde Venezuela, Colombia ha recibido recientemente según (Vargas, 2018) y el Informe Proyecto (Migración Venezuela, 2018), cuatro desplazamientos emigratorios: La i) se realizó entre 1999 y 2005, compuesta principalmente por representantes de los sectores empresariales y políticos venezolanos; ii) entre 2005 y 2009, empresarios y profesionales del sector petrolero debido al paro petrolero y en represalias se realizaron despidos masivos de empleados de la empresa estatal Petróleos de Venezuela S.A (PDVSA); iii) entre 2010 y 2014, profesionales y estudiantes de clase media de distintas disciplinas; iv) desde 2015 hasta hoy, diáspora de sobrevivencia, de clase media y población pobre y vulnerable. Esta situación es nueva para Colombia, porque en los años precedentes era dadora de migrantes para Venezuela, en los actuales momentos se ha convertido en receptora de inmigrantes y retornados del gran país petrolero.

Los factores sociales, políticos y económicos han sido decisivos para los venezolanos en el momento de emigrar, esto a causa de la crisis de institucionalidad que pervive en esta nación suramericana. El actual mandatario Nicolás Maduro Moros, al ser uno de los alfiles del extinto Hugo Chávez Frías, consideró necesario continuar con un proyecto de gobierno al que se denominó socialismo del siglo XXI, en el que básicamente destaca la socialización de los medios de producción como modelo económico. En dicho sistema se refuerza la idea de una política al servicio de los más necesitados, según (Geovo et al., 2018), el sistema político se ha basado en un esquema populista, fundado en que la soberanía descansa en el pueblo y que está por encima de los representantes que ellos han elegido.

No obstante, en la realidad se ha dado la erosión del sistema democrático, que según (Jácome, 2010), se debe porque la conducción de las políticas públicas y de todo el sistema político se está orientando a través de procesos sociales que no se consideran democráticos como lo son por ejemplo: el proceso de colectivizar los medios de producción, estatizando todo el sistema hasta el punto de intervenir y controlar las esferas más privadas de los ciudadanos como las comunicaciones, bienes, servicios, salud, alimentación y educación.

Otro indicador relacionado con la insatisfacción de la población y las detracciones al sistema político es la percepción en la distribución de la riqueza. Desde hace cinco años que independiente de las tasas de crecimiento económico de cada país, la percepción de justicia en la distribución de la riqueza cae de 25\% 
en 2013 a 16\% en 2018. Estos resultados indican que no importa la riqueza ni el crecimiento económico, sino como se distribuye en la población (Informe Latino Barómetro, 2018).

Precisa advertirse, que las condiciones hasta el momento reseñadas conducen a que inexista un sistema democrático. El cual no debe, ni puede restringirse a una concepción meramente electoral, pues se sabe que el actual mandatario de Venezuela adviene al poder a través de mecanismos de participación ciudadana; no obstante, si se quiere tener una consideración integra de la democracia, implica una conjugación de elementos cualitativos que redundan en función de la pluralidad, así las cosas si por ejemplo, nos fijamos en la experiencia económica de este país se notará la monopolización que el estado hace de este sector, impidiendo el surgimiento del desarrollo particular. (Geovo et al., 2018) afirma que, la democracia económica implica mercados libres, libertad cambiaria, garantías a la propiedad privada, seguridad y justicia sólida y confiable, sin estos elementos las democracias resultan incompletas e insatisfactorias.

\section{Venezolanos en el municipio de Sabanalarga, Atlántico}

El municipio de Sabanalarga se encuentra ubicado en la Costa norte de Colombia, a $42 \mathrm{kms}$ de Barranquilla, cuenta con una población de 84.410 habitantes. Su actividad económica más importante es la ganadería, además del surgimiento de pequeñas y medianas empresas, lo cual la convierten en un sitio propicio para el crecimiento económico y donde las personas de zonas aledañas e inmigrantes han encontrado la satisfacción de necesidades básicas.

De acuerdo a la información recabada en la presente investigación se obtuvieron algunos datos fundamentales para comprender de forma palmaria la situación arrostrada, en cuanto a la inmigración de ciudadanos venezolanos, en el municipio de Sabanalarga. De esta manera a través del enlace de víctimas, oficina dependiente de la administración local, se pudo establecer lo siguiente: en el año 2019, se registraron 3995 (Gráfica 1), correspondiente a 1500 venezolanos sin arraigo, es decir sin ascendientes colombianos. Por otra parte, existen 2495 con arraigo procedentes de familias colombianas (colombo-venezolanas). En cuanto al crecimiento de la población de inmigrantes venezolanos se censaron 506 embarazadas y 4 casos de VIH.

Gráfica 1. Diciembre 2019.

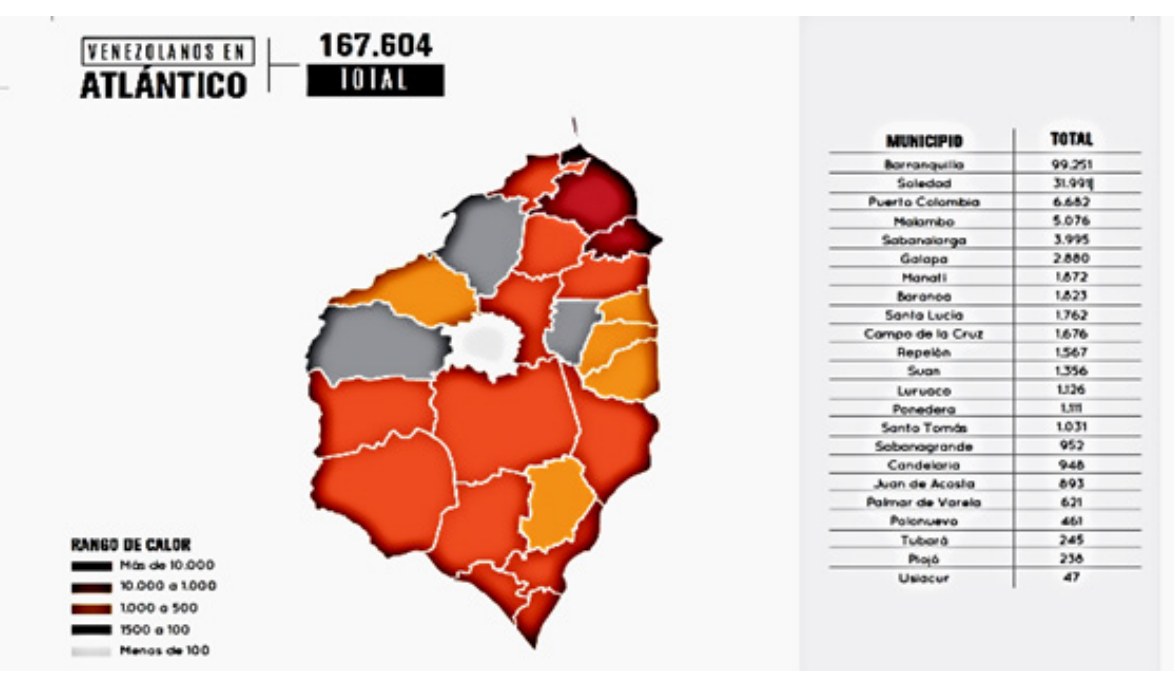

Fuente: Migración Colombia. 
Es perentorio aclarar las denominaciones de arraigo o sin arraigo. La primera de ella alude a personas nacidas en Venezuela, con ascendencia colombiana como padres o abuelos; los segundos son aquellos que sin ningún tipo de lazo consanguíneo decidieron emigrar a territorio colombiano, en muchos casos por la cercanía geográfica. Específicamente llegan al municipio de Sabanalarga iniciando una travesía que va desde el departamento de la Guajira, el Magdalena y finalmente el Departamento del Atlántico.

Otra de los aspectos que conviene describir es lo atinente a la información obtenida en el trabajo de campo, a través del enlace de victimas dependencia creada para la atención de víctimas del conflicto armado interno, sin embargo en el periodo del 2018 a 2019 por orden del ente territorial, prestó atención a la población de inmigrantes venezolanos colaborando a la gobernación del Atlántico y a la ACNUR en jornadas integrales de salud, medicamentos, entrega de mercados y actividades correspondientes a jornadas de tutelas sobre el derecho a la identificación.

A continuación, se referencia a detalle los datos suministrados por el informante clave; Señor Fredy Castro, funcionario de esta dependencia, sobre los barrios en los cuales se encuentra residenciado la población migrante: Primero de Diciembre, 31 de Enero (Invasión), 11 Febrero (Invasión), La Paz (Invasión), Villa Galindo (Invasión), 7 de Agosto, Evaristo Surdís Santa Rosa; y los Corregimientos: La Aguada, Colombia, La Peña, Cascajal.

Habida cuenta de lo anterior, se evidencia que la información se obtuvo de una dependencia que, a juicio de su denominación, no tiene como función principal suministrarla. Peculiaridades de este tipo suelen presentarse en toda investigación cuando se valida la información obtenida de la teoría con la praxis. Como lo afirma (Aguirre, 2017) el proceso de campo se transforma en producto al ser interpretado por el investigador, en la que lo narrado e interpretado obtiene la afirmación de verdad descubierta.

\section{Tránsito de venezolanos desde Colombia a otros países de América}

La crisis humanitaria experimentada por Venezuela no excluye a ningún país de la región por la situación migratoria, en consecuencia existen colonias de venezolanos en diferentes naciones del continente americano.

Es importante resaltar que Colombia no solo es advertida por los migrantes venezolanos como su sitio de destino definitivo, sino que al ser un país geográficamente estratégico para la movilidad funciona como "corredor natural" de los inmigrantes. Tomando en cuenta la información suministrada por organizaciones como la ACNUR (2019), (Agobian, 2018), (Toro, 2019). (Tabla 1)

TABLA 1 VENEZOLANOS DISTRIBUIDOS POR PAÍS DE DESTINO 2018-2019

(ACNUR, 2019), *(AgOBIAN, 2018), **(TORO, 2019)

\begin{tabular}{|c|c|}
\hline \multicolumn{2}{|c|}{ Distribución de migrantes venezolanos por país de destino } \\
\hline Colombia & 1,3 millones \\
\hline Perú & 768.000 \\
\hline EEUU & $418366^{*}$ \\
\hline Ecuador & 263.000 \\
\hline España & $323.575^{*}$ \\
\hline Portugal & $24.603^{* *}$ \\
\hline Italia & $49.831^{\text {** }}$ \\
\hline Canadá & $20.775^{\star *}$ \\
\hline
\end{tabular}




\begin{tabular}{|c|c|}
\hline Argentina & 130.000 \\
\hline Chile & 288.000 \\
\hline Panamá & $94.400^{* *}$ \\
\hline Brasil & 168.000 \\
\hline México & $39.500^{* *}$ \\
\hline Otros & 361.023 \\
\hline TOTAL & 3.000 .000 \\
\hline
\end{tabular}

Fuente: Elaboración propia

Para fomentar la discusión bibliográfica se puede resaltar las siguientes investigaciones:

(Vargas, 2018), opina que las condiciones internas de Venezuela en cuanto a la baja calidad de vida que tienen actualmente los venezolanos trae como consecuencia la elevada emigración tanto de profesionales como de gente sin ninguna calificación laboral, que en la línea del tiempo dejará el país sin el capital humano necesario para activar los procesos de desarrollo desde todo punto de vista. Así mismo. Los estados fronterizos y de más allá no estaban preparados para recibir esta migración intensiva.

(Ross, 2017), expresa en su estudio sobre Migración, globalización y su impacto en Chile, que éstos pasaron de ser donantes de migrantes a receptor de migrantes. Puesto que, el Estado chileno no ha estado preparado para una migración masiva de venezolanos, a raíz de esto se presentan muchos problemas y entre esos se presenta ¿el cómo estudiar y abordar dicha migración?, por los momentos las instituciones y la sociedad chilena solo ven una situación problemática obviando los beneficios que les puede traer dicha migración debiéndose tratar desde otro punto de vista y verlo también como una oportunidad.

\section{Política de legalización de los venezolanos en el territorio colombiano}

Durante la presidencia de Juan Manuel Santos se promulgó el Permiso Especial de Permanencia (PEP) a los venezolanos que se encontraban en el territorio colombiano desde del 25 de julio de 2017, que hubiesen entrado legalmente por el control fronterizo con pasaporte. Fue una manera de regularizar la migración de venezolanos y dar un basamento jurídico a su permanencia para garantizar la estabilidad jurídica, laboral, el acceso a la salud, a la educación.

A continuación se presentan las resoluciones que han sido decretadas durante el segundo gobierno de Santos (2014- agosto del 2018) y en el mandato de Iván Duque Márquez, actual presidente de Colombia (Tabla 2):

TABLA 2 PROYECTA LAS RESOlUCIONES EXPEDIDAS POR EL MINISTERIO DE RELACIONES EXTERIORES, Y LAS EXPEDIDAS POR LA UNIDAD ADMINISTRATIVA LAS CUALES AMPLÍAN CONTENIDO.

\begin{tabular}{|l|l|}
\hline Resoluciones Ministerio de Relaciones Exteriores & \multicolumn{1}{c|}{$\begin{array}{c}\text { Resoluciones Unidad administrativa especial de } \\
\text { Migración-Colombia }\end{array}$} \\
\hline 5797,25 de julio 2017 & 1272,28 de julio 2017 \\
\hline 0740, 05 febrero 2018 & 0361,06 febrero 2018 \\
\hline 10677,18 diciembre 2018 & 3317,19 diciembre 2018 \\
\hline 0240,23 enero 2020 & 0238,27 enero 2020 \\
\hline
\end{tabular}

Fuente: Elaboración propia. 
El cuadro presenta la relación de los actos administrativos expedidos por el Ministerio de relaciones exteriores, los cuales ordenan a la Unidad administrativa especial de Migración-Colombia expedir resoluciones internas que establezcan mecanismos y condiciones no contenidas en los actos administrativos.

Igualmente, el Ministerio del trabajo; con el decreto número 117 del 28 de enero de 2020, crea un Permiso Especial de Permanencia para el fomento de la formalización (PEPFF) con la finalidad de impulsar la regularidad de los inmigrantes venezolanos que no posean permiso de permanencia, ni visa de trabajo en el territorio colombiano, su regularización se hará a través de ofertas de contratos laborales o de prestación de servicios, con solo presentar la cédula de identidad venezolana o el pasaporte mismo si están vencidos, ser mayor de edad, no presentar antecedentes judiciales tanto en Colombia como en el exterior, que no tenga medida administrativa de expulsión o deportación vigente.

\section{Migración Venezolana y Salud}

Debido a los altos niveles de vulnerabilidad que presenta el fenómeno migratorio venezolano. Es de gran importancia conocer las políticas gubernamentales de Colombia para contrarrestar a la inmigración masiva de sus vecinos en cuanto a la protección y la prestación de servicios de salud.

Con el propósito de atender los problemas de salud de los inmigrantes el estado colombiano ha tomado una serie de medidas para favorecerlos fundamentándose en el artículo 49 y 100 de la Constitución Política de Colombia, igualmente los artículos 3 y 156 literal b), de la Ley 100 de 1993, así como, artículo 32 de la Ley 1438 de 2011 y el artículo 6 de la Ley 1751 de 2015, en este ordenamiento según (MINSALUD, 2019), se establece la garantía irrenunciable del derecho a la salud para todos los ciudadanos colombianos y extranjeros que residan en la República. De allí que toda persona sea nacional o extranjera tiene por igualdad el derecho a recibir dicha atención como lo consagran las siguientes Leyes; artículo 168 de la Ley 100 de 1993, en concordancia con el artículo 67 de la Ley 715 de 2001. Del mismo modo, la Sentencia C-834/07 reitera que en jurisprudencia constante, la Corte Constitucional sostiene que se le otorga la asistencia necesaria a toda persona que se encuentre en el territorio colombiano.

La Ley 1751 de 2015 en sus artículos 10 y 14 consagra los derechos y deberes de los usuarios referentes a la prestación de servicio de salud, en atención a las urgencias, como obligación de todas las instituciones prestadoras de servicios de salud (IPS). (MINSALUD 2019, p 28.)

En el caso de la asistencia, garantía, y el derecho a la salud de niñas, niños y adolescentes el código de infancia y adolescencia, Ley 1098 de 2006, en el artículo 27 se determina que los menores tienen derecho a la salud integral. Al respecto, el Ministerio de Salud y Protección Social (MSPS) ha emitido una serie de circulares en el periodo 2014- 2018 para la vigilancia de la salud pública atendiendo la migración masiva proveniente de la República Bolivariana de Venezuela, para atenderlos y al mismo tiempo vigilancia epidemiológica para prevenir la propagación de enfermedades contagiosas.

Durante el gobierno de Juan Manuel Santos se implementaron políticas públicas con el objetivo de fortalecer las regiones fronterizas, en el marco del plan nacional de desarrollo prosperidad para todos, en dicho documento contempla lo siguiente:

La incorporación, de las áreas fronterizas, terrestres y marítimas como elemento esencial de propósito nacional para el desarrollo. Así mismo, dispuso promocionar el diseño de políticas públicas que reconozcan las particularidades de las regiones fronterizas 
identificando sus activos sociales y naturales como recursos estratégicos y de oportunidad para un desarrollo endógeno de las regiones fronterizas y para el impulso de la competitividad del país. (DNP, 2014, p.66)

Para favorecer el apoyo económico de las zonas fronterizas, que a la postre fueron las que más perjudicadas resultaron producto de la actividad comercial histórica y constante entre ambos países, en el año 2013 se formuló el Plan Fronteras para la Prosperidad, cuyo Objetivo fue "Impulsar el desarrollo social y económico de las regiones de frontera y su integración con los países vecinos". Sin embargo, no fue posible su materialización en favor de la República Bolivariana de Venezuela puesto que decide salir de la Comunidad Andina de Naciones en 2006. Según decisión 583 de la Comunidad Andina de Naciones de 2004. (DNP, 2014, p.66)

La jurisprudencia de la Corte Constitucional, en las sentencias SU-677 de 2017 y T-210 de 2018, ha reconocido el derecho a la salud en los inmigrantes, instando en la protección especial de la mencionada población, sin importar su condición legal en el país, especialmente a grupos vulnerables como niños, niñas y madres cabezas de hogar.

\section{Apatridia de los hijos de migrantes venezolanos nacidos en Colombia.}

Otra circunstancia problemica que tienen que enfrentar los inmigrantes venezolanos está relacionado con la situación legal de sus hijos nacidos en territorio colombiano, ya que en este país la Registraduría Nacional del Estado Civil, les ha negado la nacionalidad, dejándolos en una condición de ilegalidad y desprotección al no tener garantías de sus derechos fundamentales o amparo de ningún estado. Este fenómeno se denomina como apatridia. Según (Robert, Rey, \& Rey-Debove, 2018), es un término utilizado a partir de 1930, situación de una persona apátrida. Este vocablo se deriva de apátrida que proviene del griego antiguo öாатрıь, ápatris (sin patria), significa una persona desprovista de nacionalidad legal que ningún Estado considera como nacional.

En el marco normativo internacional se consagra la apatridia en el artículo 1 de la Convención sobre el estatuto de las personas apátridas de las Naciones Unidas aprobada en Nueva York, el 28 de septiembre del año 1954, posteriormente fue aprobada el 30 de agosto de 1961, la Convención para reducir los casos de Apatridia, estas convenciones fueron adoptadas por Colombia según Ley 1588 de 2012.

Según la ACNUR, la apatridia no puede soslayarse, debido a que a las personas que enfrentan esta situación se les tiene que otorgar canales de acceso para que puedan ser atendidas, por consiguiente resulta imposible considerar a una sociedad justa y equitativa cuando hay un grupo poblacional en un grado de ingente de exclusión.

Como se ha venido desarrollando el presente artículo concierne al caso de migrantes venezolanos en Colombia. Por tal razón es conveniente aludir al tema de la apatridia, máxime cuando existe población de especial protección como son los niños. En este sentido, se precisa hacer alusión directa a la normatividad constitucional tanto de Venezuela como Colombia a fin de determinar lo dispuesto por estos estados en relación al tema de nacionalidad. Cabe manifestar que ambas legislaciones adoptan del derecho romano los mismos sistemas para consideración de la nacionalidad; ius sanguinis y ius soli,

De acuerdo a la (Constitución Venezolana, 1999), en el Capítulo II, referente a la Nacionalidad y la ciudadanía en su sección primera, artículo 32, parágrafo 2, expresa que son también venezolanos y venezola- 
Paola Margarita Carvajal Muñoz, Beliña Anner Herrera Tapias, Eduardo Antonio Palencia Ramos, Mireya Peréz Núñez, Jessica Vera Carrera

nas por nacimiento: "Toda persona nacida en territorio extranjero, hijo o hija de padre venezolano por nacimiento y madre venezolana por nacimiento".

Pese a lo que determina la norma constitucional venezolana se generan múltiples inconvenientes al momento de presentar legalmente al recién nacido, entre ellos las restricciones de la autoridad consular venezolana, debido a que realiza exigencias muy difíciles de cumplir por personas que se encuentran en situaciones económicas precarias, aunado a que en muchos casos, centenares, emigraron de su país de origen sin tomar en cuenta previsiones de ningún tipo y por ende sin contar con la documentación requerida como el pasaporte entre otros.

Ante la notoria complejidad el ciudadano venezolano tendría que devolverse a su país para iniciar un trámite de registro, en el cual se requieren documentos para verificar que efectivamente existe un lazo consanguíneo con el menor y su nacimiento en territorio extranjero, además de los respectivos pasaportes, tal como fue señalado por el servicio (Jesuita, 2019). Está claro que estas personas transitan por un camino sinuoso y los países no les otorgan el debido amparo por lo tanto, carecen de una efectiva garantía de derechos.

Por consiguiente, debido a la crisis socio económico y político actual en Venezuela, así como la ruptura de relaciones diplomáticas o consulares con Colombia desde el año 2015, se complica el registro de los niños y niñas tanto en Venezuela como en Colombia, país de recibimiento.

(La Constitución de Colombia, 1991), en el Título III, sobre los habitantes y el Territorio, en el Capítulo 1, refiriéndose a la Nacionalidad colombiana en el artículo 96 formula lo siguiente, son colombianos según numeral 1.Por nacimiento, inciso a) “Los naturales de Colombia, con una condición: que el padre o la madre hayan sido naturales o nacionales colombianos o que, siendo hijos de extranjeros, alguno de sus padres estuviere domiciliado en la República en el momento del nacimiento".

La constitución colombiana, de acuerdo a los principios que en ella se encuentran contenidos se funda en el respeto a la dignidad humana; en conexión directa a los derechos fundamentales, (Silveira, 2013) e importante para la consolidación de Colombia como estado constitucional, (Palencia, Herrera y Carvajal, 2018), ello quiere decir que todas las autoridades públicas o privadas deben encaminar el sentido de sus funciones hacia el favorecimiento de los derechos originarios del ser humano, en ese orden de ideas quien la interpreta no debe hacerlo excluyendo dichos principios, su hermenéutica debe ser sistemática. En razón de lo anterior es posible determinar que aun cuando la constitución política establece el otorgamiento de nacionalidad a los hijos de ciudadanos extranjeros que estuvieren domiciliados en territorio colombiano, las entidades causaron un detrimento al no reconocerlo.

Habida cuenta de lo anterior, se ejercen mecanismos de defensa en favor de derechos fundamentales como la acción de tutela el cual busca desvirtuar la interpretación errónea hecha por la Registraduría, por ende, se cita la Sentencia de la Corte Constitucional T-006/2020, para el otorgamiento de la nacionalidad colombiana por nacimiento a menores de progenitores extranjeros. A continuación se enuncian las consideraciones relevantes dadas por el Alto Tribunal Constitucional:

- Se acusa a la Registraduría del Estado Civil de realizar una interpretación inconstitucional referente al alcance del requisito del domicilio regulada a través del artículo $2^{\circ}$ de la Ley 43 de 1993, que en su tercer inciso establece que "por domicilio se entiende la residencia en Colombia, acompañada del ánimo de permanecer en el territorio nacional de acuerdo con las normas del Código Civil" 
- Señala la Corte Constitucional que la Registraduría Nacional de Estado Civil aplicó una interpretación inconstitucional del requisito de domicilio, empleando la norma que corresponde a la adquisición de nacionalidad por adopción y requiriendo que los padres extranjeros le hayan otorgado una visa, no tomando ni siquiera en cuenta el Permiso Especial de Permanencia que Colombia otorgó a los venezolanos para que estuvieran de forma regular en su territorio además este permiso les da la oportunidad de trabajar de forma legal.

- Ahora bien, según las tutelas antes mencionadas, dicha exégesis es contraria a la doctrina constitucional que fortalece el derecho a la igualdad y no discriminación (Artículo 13), "el derecho a la nacionalidad de los niños (artículo 44, 96) (...) los extranjeros disfrutarán de los mismos derechos que se conceden a los nacionales (artículo 100). (...) esta actuación de la Registraduría es contraria a las disposiciones de la Ley 43 (artículo $2^{\circ}$ ), el Código Civil colombiano.

- Por consiguiente, el requisito del domicilio se cumple cuando están presentes los elementos de residencia y ánimo de permanencia de acuerdo con lo establecido en 2o de Ley 43 de 1993 y el Código Civil, por lo que la prueba del domicilio NO está sujeto a la titularidad de una visa tipo M o tipo R. En consecuencia, no se podrá negar la nacionalidad por nacimiento a ningún niño o niña nacido en Colombia a causa de que sus padres extranjeros no tengan una visa

- También, va en contra de los acuerdos internacionales del Estado colombiano de protección y garantía del derecho a la nacionalidad, al interés superior de los niños y las niñas, y la prevención de la apatridia de acuerdo Convención sobre el Estatuto de los Apátridas de 1954, la Convención para Reducir los Casos de Apatridia de 1961, la Convención de Derechos del Niño, Artículo 7 de la (CIDNN, 1990), la protección del menor ha sido enunciada de acuerdo a (Beloff, 2009), desde 1924 en la Declaración de Ginebra sobre los Derechos del Niño y en la Declaración de los Derechos del Niño adoptada por la Asamblea General el 20 de noviembre de 1959, y reconocida en la Declaración Universal de Derechos Humanos, en el Pacto Internacional de Derechos Civiles y Políticos (en particular, en los artículos 23 y 24), en el Pacto Internacional de Derechos Económicos, Sociales y Culturales (en particular, en el artículo 10) y en los estatutos e instrumentos pertinentes de los organismos especializados y de las organizaciones internacionales que se interesan en el bienestar del niño.

De esta manera, el Estado colombiano interesado en la prevención de estos casos de apatridia, implementó a través de la Resolución 8470 de 5 de agosto 2019, se adopta una medida administrativa de carácter temporal y excepcional para incluir de oficio una nota que especifique; Válido para demostrar nacionalidad en los Registros civiles de nacimiento de cada niño y niña nacidos en Colombia, que presenten un riesgo de apatridia, hijos de padres venezolanos en concordancia con la aplicación del artículo 96 de la (CPC, 1991), obviando la interpretación inconstitucional del Registro Civil sobre el domicilio y la visa obligatoria del ciudadano extranjero residenciado en Colombia.

\section{CONCLUSIONES}

Mediante la realización del presente artículo se puede concluir lo siguiente:

La migración es un fenómeno que ha afectado a los diversos países en el mundo, este se presenta fundamentalmente por las crisis económicas y sociales que experimentan algunas naciones cuando sus ciudadanos deciden abandonar su lugar de origen para ir a otro geográficamente cercano a fin de encontrar la satisfacción de sus necesidades básicas. 
El caso de Venezuela resulta peculiar por dos razones: la primera, el resquebrajamiento de la institucionalidad política, producto de un gobierno que resalta por su negligencia y visos autoritarios, lo cual conlleva a que se adviertan cercenados derechos y libertades en individuos en su mayoría opositores. Sin embargo, el déficit económico ha afectado a la mayoría de la población, indiferentemente, de su ideología política, en ese sentido hace que el éxodo sea mayoritario. La segunda, radica en que paradójicamente este país históricamente fue receptor ya que gozaba durante la década de los 70' de una riqueza económica producto de la explotación petrolífera.

No es la primera vez que Venezuela experimenta una situación económica turbulenta durante la década de los 80' muchos ciudadanos extranjeros residentes en este país abandonaron el territorio, precisamente porque no hallaban la consecución de sus objetivos primarios, no obstante, pese a la gravedad, no tuvo las dimensiones que en la actualidad reviste. Lo cual permite establecer que la magnitud arrostrada en estos tiempos sobrepasa cualquier evento anterior, además de poner en situación de riesgo a las personas de especial protección como niños y ancianos.

Colombia posee una connotación binaria en este acontecimiento migratorio primeramente, porque se advierte a esta nación como corredor estratégico para llegar a otros países como destino final, y en segunda medida se ha transformado en el lugar de mayor recepción de venezolanos por ser país fronterizo, anejamente no se descarta que al ser naciones con rasgos históricos, sociales muy estrechos coexistan lazos de familiaridad entre sus habitantes.

Cabe también expresar, que los ciudadanos venezolanos en Colombia y particularmente en municipios del Departamento del Atlántico como Sabanalarga, pueden encontrar en algún sentido la satisfacción de sus necesidades básicas pues la administración local ha diseñado, en vista del flujo migratorio ingente programas especiales para tal fin consustanciado con la políticas públicas emanadas en el gobierno de Juan Manuel Santos en cuanto a legalización de venezolanos, la prestación del servicio a la salud y jornadas de identificación, en colaboración con la ACNUR y Gobernación del Atlántico.

Pese a las políticas públicas puestas en ejecución por el gobierno colombiano aún subsisten irregularidades y un mal ejercicio de la Registraduria Nacional del Estado Civil que se habia negado a reconocer la nacionalidad específicamente a los recién nacidos en territorio colombiano de padres venezolanos. Este fenómeno denominado apatridia se presentó por una interpretación errónea de la carta política colombiana amén de los tratados y convenios internacionales. Sin embargo, la Corte Constitucional en su loable hermenéutica ampara los derechos fundamentales de estas personas, confirmando el derecho de nacionalidad de los menores.

En los estados receptores se deben garantizar los derechos de los inmigrantes, tomando en cuenta, los tratados internacionales y la norma constitucional interna cuyo fundamento es la dignidad humana, además deben preconizar por proscribir cualquier vestigio xenófobo y discriminador en sus connacionales. Evitar este tipo de acontecimientos será significativo para el progreso de las sociedades y la convivencia armónica. 


\section{Referencias bibliográficas}

Agobian J. (2018). Estudio: Hay venezolanos en 49 estados de EE.UU. octubre 03, 2018 Recuperado de: https://www.voanoticias.com/a/venezolanos-en-49-de-50-estados-de-estados-unidos-eeuuvenezuela/4597900.html

Aguirre, Á. (2017). Cuestionarios. En O. Amat, \& A. Rocafort, Como Investigar (pág. 191). España: Profit.

Álvarez, R. (2007). Evolución histórica de las migraciones en Venezuela. Breve recuento Aldea Mundo, vol. 11, núm. 22, noviembre-abril, 2007, pp. 89-93 Universidad de los Andes Táchira, Venezuela. Recuperado de: http://www.redalyc.org/articulo.oa?id=54302209

Beloff, M. (2009). Los derechos del niño en el sistema Interamericano, Ciudad Autónoma de Buenos Aires: Del Puerto, 2009, ISBN 978-987-9120-65-1. Recuperado de: http://www.corteidh.or.cr/tablas/25897r. pdf

Basilio, C. (2009). La construcción social de las juventudes. Revista de Ciencias Sociales, (25), 21-33. ISSN: 0797-5538. Recuperado de: https://www.redalyc.org/articulo.oa?id=4536/453644787003

Constitución Política de Colombia 1991. Ediciones ECOE. Bogotá

Constitución Venezolana 1999. Recuperado de: https://observatorioplanificacion.cepal.org/sites/default/ files/instrument/files/constitucion_venezuela.pdf

Congreso Nacional de la República de Colombia. Ley 43 de 1993. Recuperado de: http://www.secretariasenado. gov.co/senado/basedoc/ley_0043_1993.html

Congreso Nacional de la República de Colombia. Ley 1098 de 2006. Recuperado de: http://www. secretariasenado.gov.co/senado/basedoc/ley_1098_2006.html

Congreso Nacional de la República. Ley 1588 de 2012. Recuperado de: http://www.secretariasenado.gov.co/ senado/basedoc/ley_1588_2012.html

Consejo Andino de Ministros de Relaciones Exteriores. Decisión 583 Sustitución de la Decisión 546, Instrumento Andino de Seguridad Social. Recuperado de: http://www.sice.oas.org/trade/JUNAC/ decisiones/DEC583s.asp

Corporación Latino barómetro (2018). Informe 2018. Recuperado en: file:///C:/Users/PC-HP/Downloads/ INFORME_2018_LATINOBAROMETRO\%20(1).pdf

Corte Constitucional de Colombia. Sentencia de la T-006/2020. Recuperado de: https://www. corteconstitucional.gov.co/Relatoria/2020/T-006-20.htm

DNPepartamento Nacional de Planeación. (2010). Plan Nacional de Desarrollo

Prosperidad para Todos 2010 - 2014. Recuperado de: https://colaboracion.dnp.gov.co/CDT/Sinergia/ Documentos/Balance_de_Resultados_PND_2010_final.pdf

Departamento Nacional de Planeación (2014) Consejo Nacional de Política Económica y Social. CONPES. Prosperidad para las Fronteras de Colombia. Recuperado de:https://colaboracion.dnp.gov.co/CDT/ Conpes/Econ\%C3\%B3micos/3805.pdf

Departamento Nacional de Planeación (2018) Estrategia para la atención de la migración desde Venezuela. (Documento CONPES 3950). Recuperado de: https://colaboracion.dnp.gov.co/CDT/ Conpes/Econ\%C3\%B3micos/3950.pdf

Durand, J. (2009). Processes of Migration in Latin America and the Caribbean (1950-2008). University of Guadalajara, Centro de Investigación y Docencia, Económica (CIDE). MPRA Paper No. 19207, posted 12 Dec 2009 14:56 UTC. United Nations Development Programme Human Development Reports Research Paper. Recuperado de: https://mpra.ub.uni-muenchen.de/19207/ 
Paola Margarita Carvajal Muñoz, Beliña Anner Herrera Tapias, Eduardo Antonio Palencia Ramos, Mireya Peréz Núñez, Jessica Vera Carrera

Geovo, A.; Paz, S. y Pérez, M. (2018). Debilidades de la Democracia y el Sistema Político Latinoamericano. Revista venezolana de tecnología y sociedad. Vol.11, N.1. Enro-junio.

Gutiérrez, I. (2011). El debate científico sobre Migración Internacional y Desarrollo. Colección: Centro de Estudios de Migraciones Internacionales - Editorial CEMI. http://biblioteca.clacso.edu.ar/Cuba/cemiuh/20110720124104/CLACSOIVIS.pdf

Hernández, C. (2015). Nuevos recursos para la investigación cualitativa: Software gratuito y herramientas colaborativas. Revista Opción, Año 31, No. Especial 5 (2015): 453 - 471 ISSN 1012-1587 Recuperado de: https://produccioncientificaluz.org/index.php/opcion/article/view/20663/20566

Jácome, F. (2010.) Evolución/involución de la democracia en América Latina. Ildis. Instituto Latinoamericano de Investigaciones Sociales.

Migración Colombia-Departamento Nacional de Estadística (DANE, 2005-2016). Extranjeros en Colombia. Aproximación migratoria a sus trayectorias en Colombia. Primera edición. Recuperado de: www. migracioncolombia.gov.co

Migración Colombia DANE-Venezuela (2019). Recuperado de: http://www.migracioncolombia.gov.co/ venezuela

Ministerio de Relaciones Exteriores. Resolución 5797, República de Colombia, 28 de Julio 2017. Recuperado de: http://www.migracioncolombia.gov.co/jdownloads/Resoluciones/Resoluciones\%20-\%202017/ resolucion\%205797-PEP\%20venezolanos.pdf

Ministerio de Relaciones Exteriores. Resolución 0740, República de Colombia, 05 de Febrero de 2018. Recuperado de: http://www.migracioncolombia.gov.co/jdownloads/Resoluciones/Resoluciones\%20 -\%202018/RESOLUCION\%200740\%20DE\%202018\%20PEP.pdf

Ministerio de Relaciones Exteriores. Resolución 10677, República de Colombia, 18 de diciembre de 2018. Recuperado de: http://www.migracioncolombia.gov.co/jdownloads/Resoluciones/Resoluciones\%20 -\%202018/Resolucion\%2010667\%20ampliacion_plazo_pep.pdf

Ministerio de Relaciones Exteriores. Resolución 0240, República de Colombia, 23 de Enero de 2020. Recuperado de: http://www.migracioncolombia.gov.co/jdownloads/Resoluciones/Resoluciones\%20 -\%202020/Resolucion\%200240\%20del\%2023\%20de\%20enero\%20de\%2020200.pdf

Ministerio de Salud (2019) Plan de respuesta del sector salud para el fenómeno migratorio. Recuperado de: https://data2.unhcr.org/es/documents/details/70237

Ministerio de Salud. Ley 1438 de 2011, República de Colombia. Recuperado de: https://www.minsalud.gov. co/Normatividad_Nuevo/LEY\%201438\%20DE\%202011.pdf

Ministerio de Salud. Ley 1751 de 2015, República de Colombia. Recuperado de: https://www.minsalud.gov.co/ Normatividad_Nuevo/Ley\%201751\%20de\%202015.pdf

Ministerio del Trabajo (2020). Decreto 117 del 28 de enero de 2020, Permiso especial de permanencia para el fomento de la del inmigrante ilegal venezolano. (PEPFF). Recuperado de: https://dapre.presidencia. gov.co/normativa/normativa/DECRETO\%20117\%20DEL\%2028\%20DE\%20ENERO\%20DE\%202020.pdf

Ortín, J. (2019). Migraciones. Desarrollos teóricos, evidencias empíricas y consistencias conceptuales, octubre 2019. Proyecto Migración Venezuela (2018). Proyectos Semana S.A. financiado con el apoyo de la Agencia de Estados Unidos para el Desarrollo Internacional (USAID), a través del programa de Alianzas para la Reconciliación operado en Colombia por ACDI/VOCA. (Universidad del Rosario, 2018). Recuperado de: http://journals.openedition.org/polis/9296 
Palencia, E. Herrera, B. y Carvajal P. (2018). Del formalismo retributivo a la nueva concepción de justicia restaurativa en Colombia a partir de la constitución de 1991. http://dx.doi.org/10.22519/22157379.1217 Recuperado de: https://revistas.curn.edu.co/index.php/ergaomnes/article/view/1217

Robert, P. Rey, A. \& Rey-Debove, J. (2018). Apatride. Le petit Robert dictionnaire alphabétique et analogique de la langue française. Le Robert. ISBN: 978-2-32101-060-9

Ross, C. (2017). Migración, globalización y su impacto en Chile. Revista académica. Nº54.-2017-ISSN: 07124438. Recuperado de: https://www.acipol.cl/revista-academica-volumen-54.html

Servicio, Jesuita a Refugiados (2019) Intervención ciudadana en el proceso T7.206.829, correspondiente a la acción de tutela interpuesta por YAD en representación de 27 Mayo 2019, Colombia. Recuperado de: https://www.refworld.org.es/docid/5d407ca94.html

Silveira Gorski, H. (2013). Biopolítica de Estados expulsores. Política y Sociedad, 49(3), 497-517. https://doi. org/10.5209/rev_POSO.2012.v49.n3.38551

Toro, M. (2019). Ya son más de 4 millones de migrantes y refugiados venezolanos en el mundo. Recuperado en:https://cnnespanol.cnn.com/2019/06/07/mas-de-4-millones-de-migrantes-y-refugiadosvenezolanos-en-el-mundo-segun-acnur/

Unidad administrativa especial Migración Colombia. Resolución 1272, República de Colombia, 28 de Julio de 2017. Recuperado de: http://migracioncolombia.gov.co/jdownloads/Resoluciones/Resoluciones\%20 -\%202017/Resolucion\%201272\%20de\%202017.pdf

Unidad administrativa especial Migración Colombia. Resolución 0361, República de Colombia, 06 de Febrero de 2018. Recuperado de: http://migracioncolombia.gov.co/jdownloads/Resoluciones/ Resoluciones\%20-\%202018/RESOLUCION\%200361\%20DE\%202018\%20PEP.pdf

Unidad administrativa especial Migración Colombia. Resolución 3317, República de Colombia, 19 de Diciembre de 2018. Recuperado de: http://migracioncolombia.gov.co/jdownloads/Resoluciones/ Resoluciones\%20-\%202018/Resoluci\%C3\%B3n\%203317\%20de\%2019-12-2018\%20implementa\%20 nuevo\%20t\%C3\%A9rmino\%20PEP\%20(3).pdf

Unidad administrativa especial Migración Colombia. Resolución 0238, República de Colombia, 27 de Enero de 2020. Recuperado de: http://www.migracioncolombia.gov.co/jdownloads/Resoluciones/ Resoluciones\%20-\%202020/Resoluci\%C3\%B3n\%200238\%20del\%2027\%20de\%20enero\%20de\%20 20200.pdf

Vargas, C. (2018). La migración en Venezuela como dimensión de la crisis. Pensamiento propio 47. Enerojunio 2018, año 23 (91-128). Publicación Trilingüe de Ciencias Sociales de América Latina y El Caribe. Recuperado en: http://www.cries.org/wp-content/uploads/2018/09/009-Vargas.pdf 